\title{
Throttleless control of SI engine load by fully flexible inlet valve actuation system
}

\begin{abstract}
A system with independent, early inlet valve closure (EIVC) has been analysed. The open, theoretical cycle has been assumed as a model of processes proceeding in the engine with variable inlet valve actuation. The system has been analysed individually and comparatively with open Seiliger-Sabathe cycle which is theoretical cycle for the classic throttle governing of engine load. The influence of EIVC on fuel economy, cycle work, relative charge exchange work and cycle efficiency has been theoretically investigated. The use of the analysed system to governing of an engine load will enable to eliminate a throttling valve from inlet system and reduce the charge exchange work, especially within the range of partial load. The decrease of the charge exchange work leads to an increase of the internal and effective works, which results in an increase of the effective efficiency of the spark ignition engine.
\end{abstract}

Key words: spark-ignition engine, variable valve actuation, early inlet valve closure, theoretical cycle, charge exchange process, cycle efficiency

\section{Introduction}

Realization of a charge exchange process in a combustion engine requires surmounting flow resistances in inlet and exhaust systems so execution of an adequate work co-called the charge exchange work. A charge exchange system have an essential impact on effectiveness of the engine work. Each element installed in the charge exchange system generates flow resistance of a fresh charge in a intake system and combustion products in a exhaust system. These resistances bring about an increase of the charge exchange work which contributes to a decrease of the internal and the effective work of an engine. Increase of the charge exchange work for partial load in the spark-ignition engine is connected with a method of load control. Quantity governing with the aid of a throttle, installed in an intake system, is disadvantageous especially from thermodynamic point of view because throttling generates exergy losses [1].

Increasing the energy efficiency of an internal combustion engine with spark ignition is possible by eliminating the throttle. This may be accomplished by using fully independent control of intake or/and exhaust valves [3-5]. The most flexible solution for independent control of the valves is to use electromagnetic actuators but they are still under construction and are not in mass production because of electro-mechanical problems [6, 7]. However, currently the most advanced solution is an electro-hydraulic system [8-10].

Fully independent valve drive enables engine load control according to different, the following strategies $[2,3]$ - late inlet valve closure (the open Atkinson-Miller cycle) $[4,11-13]$, - early inlet valve closure [5],

- early exhaust valve closure,

- fully-independent both valves control.

The system with early exhaust valve closure also allows the implementation of internal exhaust gas recirculation.

Variable valve train system also allows the realization of engine operation with low inlet valve lift at partial load. The impact of the low inlet valve lift on fuel consumption and other parameters of the gasoline engine was studied by Begg et al. [14] and Clenci et al. [15].

The use of early inlet valve closure (EIVC) in the diesel engine was investigated by Zammit et al. [16]. They studied the influence of EIVC on emissions, fuel economy and exhaust gas temperature of a turbocharged, 4 cylinder common rail direct injection diesel engine. At all conditions, the effect of EIVC on fuel economy was negligible or a fuel economy penalty.

Benefits in terms of fuel economy resulting from the application of EIVC in the SI engine are significant especially under light load operating conditions because EIVC eliminates throttle from an intake system which reduces the charge exchange work.

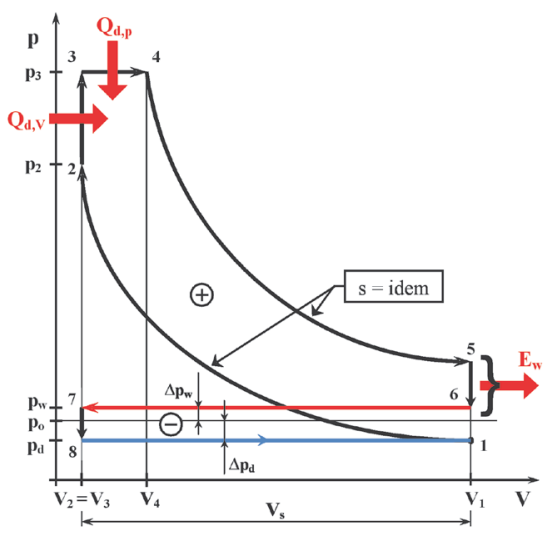

Fig. 1. Open Seiliger-Sabathe cycle, i.e. ideal cycle taking resistances in the inlet and exhaust systems into consideration

In the present study, the use of the independent inlet valve actuation has been proposed in order to increase of efficiency of the open, ideal cycle and effective efficiency of the spark-ignition engine [2]. Theoretical research of the system with early inlet valve closure (EIVC) has been carried out. The open Seiliger-Sabathe cycle (presented in Fig. 1) is the reference cycle for an assessment of advantages and effectiveness of work gaining in consequence of application of the early inlet valve closure $[4,5]$. 


\section{The system with early inlet valve closure}

\subsection{Basic characteristics of the cycle}

The open, theoretical cycle, presented in Fig. 2, has been assumed as the model of the processes proceeding in an engine with early inlet valve closure. The open cycle has been obtained by modification of the ideal cycle by addition of the processes characterizing the charge exchange.

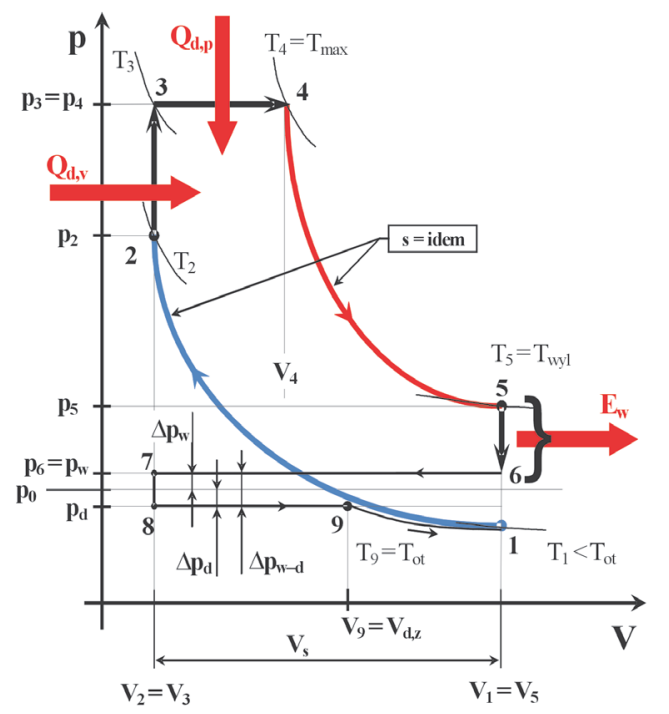

Fig. 2. The open, theoretical cycle of the system with early inlet valve closure

The volume $\mathrm{V}_{9}\left(\mathrm{~V}_{\mathrm{d}, \mathrm{z}}\right)$ of a cylinder, at which an inlet valve closure occurs during filling stroke, is the control parameter of a load (the filling). Simultaneously, this is parameter adjusting the mass of a fresh air-fuel mixture fed into a cylinder. The volume $\mathrm{V}_{\mathrm{d}, \mathrm{z}}$ can be expressed in relation to the minimum volume of the cylinder:

$$
\varepsilon_{\mathrm{d}}=\frac{\mathrm{V}_{\mathrm{d}, \mathrm{z}}}{\mathrm{V}_{2}}, \quad 1<\varepsilon_{\mathrm{d}} \leq \varepsilon
$$

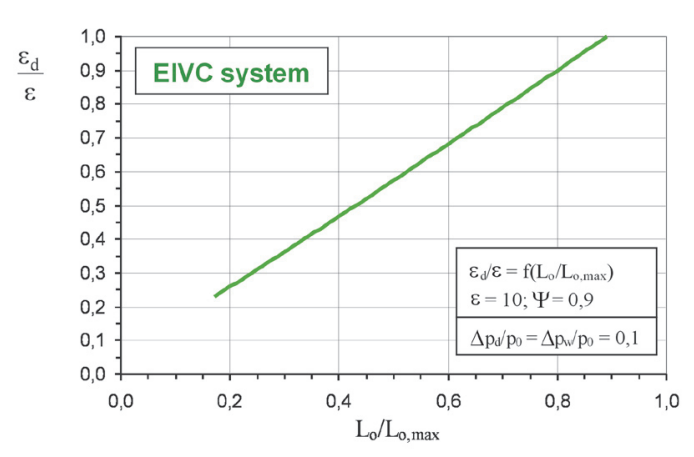

Fig. 3. Control parameter $\varepsilon_{\mathrm{d}} / \varepsilon$ of the EIVC cycle versus cycle work

The relative values of the control parameter $\varepsilon_{\mathrm{d}}$ (in relation to the total compression ratio $\varepsilon$ ) depending on the cycle work are presented in Fig. 3. Near-linear interdependence between the control parameter and the cycle work is favourable in respect of load governing.

The pressure drop $\Delta \mathrm{p}_{\mathrm{w}}$ determines the flow resistance in the exhaust system and the pressure drop $\Delta \mathrm{p}_{\mathrm{d}}$ determines the flow resistances in the intake system. In the cycle analysis, the assumption was made that the filling process finishes in the point "," at (Fig. 2):

the volume $\mathrm{V}_{\mathrm{d}, \mathrm{z}} \equiv \mathrm{V}_{9} \leq \mathrm{V}_{1}$, the pressure $\mathrm{p}_{\mathrm{d}}=\mathrm{p}_{0}-\Delta \mathrm{p}_{\mathrm{d}}$ and the temperature $\mathrm{T}_{9}=\mathrm{T}_{0}$.

\subsection{Fuel dose}

The maximum mass $m_{0}$ of the fresh charge is fed into a cylinder when intake valve closing occurs at bottom death centre, then:

$$
\mathrm{V}_{\mathrm{d}, \mathrm{z}}=\mathrm{V}_{1} \text {, that is } \varepsilon_{\mathrm{d}}=\varepsilon \text {, }
$$

and for simultaneous absence of the flow resistance in the inlet and exhaust systems:

$$
\Delta \mathrm{p}_{\mathrm{w}}=0, \Delta \mathrm{p}_{\mathrm{d}}=0 \text {, then } \mathrm{p}_{9}=\mathrm{p}_{1}=\mathrm{p}_{0} .
$$

The maximum mass of the fresh mixture can be described by the formula $[2,3]$ :

$$
\mathrm{m}_{0}=\frac{\mathrm{p}_{0} \mathrm{~V}_{1}}{(\mathrm{MR}) \mathrm{T}_{0}} \mathrm{M}_{\mathrm{m}}, \quad \mathrm{p}_{0} \approx \mathrm{p}_{\mathrm{ot}}, \quad \mathrm{T}_{0} \approx \mathrm{T}_{\mathrm{ot}}
$$

where: $\mathrm{M}_{\mathrm{m}}-$ molar mass of the fresh mixture.

For the made assumptions, the basic fuel dose amounts to:

$$
\mathrm{m}_{\mathrm{p}, 0}=\frac{\mathrm{p}_{0} \mathrm{~V}_{1}}{(M R) \mathrm{T}_{0}} \frac{\mathrm{M}_{\mathrm{m}}}{\left[1+\lambda_{0} \mathrm{n}_{\mathrm{a}, \min }^{\prime} \mathrm{M}_{\mathrm{a}}\left(1+\mathrm{X}_{\mathrm{a}}\right)\right]} .
$$

The fuel dose $m_{p}$ depends on an engine load. The basic parameters influencing the fuel dose are the following:

$\mathrm{V}_{\mathrm{d}, \mathrm{z}}$ - cylinder volume at the moment of the inlet valve closure,

$\mathrm{T}_{0}$ - temperature of the fresh charge,

$\Delta \mathrm{p}_{\mathrm{d}}$ - pressure drop in the inlet system, during filling,

$\Lambda$ - excess air ratio.

For partial load, the cylinder volume $\mathrm{V}_{\mathrm{d}, \mathrm{z}}$ ranges:

$$
\mathrm{V}_{2}<\mathrm{V}_{\mathrm{d}, \mathrm{z}} \leq \mathrm{V}_{1} \text { hence } 1<\varepsilon_{\mathrm{d}} \leq \varepsilon
$$

The flow resistances in the inlet and exhaust systems are taken into consideration:

$$
\Delta \mathrm{p}_{\mathrm{w}} \geq 0 \text { and } \Delta \mathrm{p}_{\mathrm{d}} \geq 0 \text { so } \mathrm{p}_{\mathrm{d}} \leq \mathrm{p} 0
$$

and an assumption is made that the temperature of the fresh charge is equal to the ambient temperature $\mathrm{T}_{0}$. Then, the fuel mass $\mathrm{m}_{\mathrm{p}}$ amounts to:

$$
\mathrm{m}_{\mathrm{p}}=\frac{\mathrm{p}_{\mathrm{d}} \mathrm{V}_{\mathrm{d}, \mathrm{z}}}{(\mathrm{MR}) \mathrm{T}_{0}} \frac{\mathrm{M}_{\mathrm{m}}}{\left[1+\lambda \mathrm{n}_{\mathrm{a}, \mathrm{min}}^{\prime} \mathrm{M}_{\mathrm{a}}\left(1+\mathrm{X}_{\mathrm{a}}\right)\right]}
$$

Relative fuel dose for the partial loads of an engine results from the formulas (3) and (4). For the assumption that $\lambda=$ idem, the following relation is obtained:

$$
\mathrm{m}_{\mathrm{p}}=\mathrm{m}_{\mathrm{p}, 0} \frac{\mathrm{p}_{\mathrm{d}} \mathrm{V}_{\mathrm{d}, \mathrm{z}}}{\mathrm{p}_{0} \mathrm{~V}_{1}}
$$

that can also be noted as: 


$$
\mathrm{m}_{\mathrm{p}}=\mathrm{m}_{\mathrm{p}, 0}\left(1-\frac{\Delta \mathrm{p}_{\mathrm{d}}}{\mathrm{p}_{0}}\right) \frac{\varepsilon_{\mathrm{d}}}{\varepsilon}
$$

Change of the engine load is achieved by the change of the fuel dose $m_{p}$ and the ratio $\varepsilon_{d}$ is the principal control parameter. The relative fuel dose $\mathrm{m}_{\mathrm{p}} / \mathrm{m}_{\mathrm{p}, 0}$ depending on the cycle work for the EIVC cycle is presented in Fig. 4.

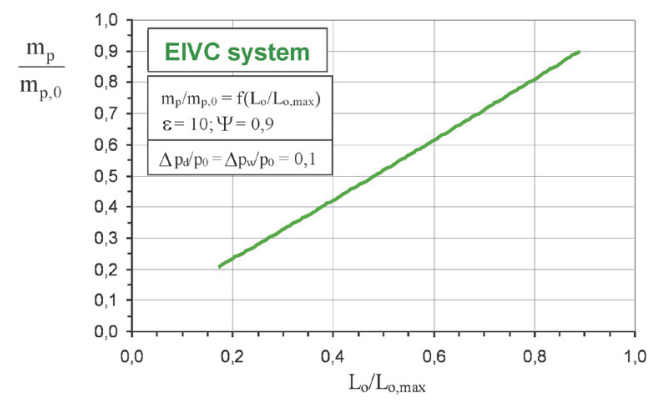

Fig. 4. Relative fuel dose $m_{p} / m_{p, 0}$ versus work for the EIVC system

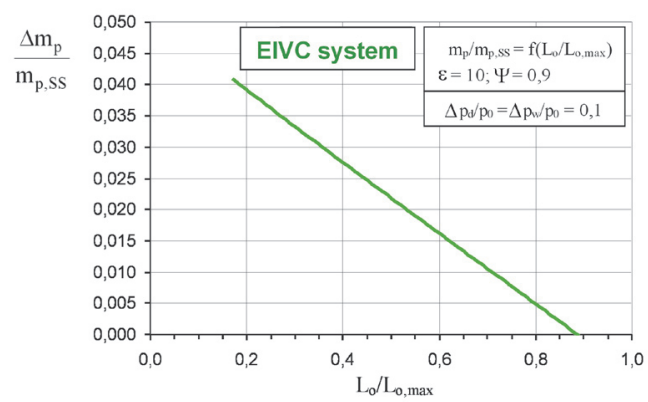

Fig. 5. Relative reduction of the fuel dose for the EIVC cycle compared to the open Seiliger-Sabathe cycle

Relative reduction of the fuel dose $\Delta \mathrm{m}_{\mathrm{p}} / \mathrm{m}_{\mathrm{p}, \mathrm{SS}}$ for the EIVC system, in comparison with the system with the classic, throttle governing (the open Seiliger-Sabathe cycle) is illustrated in Fig. 5. Using the EIVC system results in the fuel economy of up to about $4 \%$ for the lowest value of the cycle work (engine load).

\subsection{Work of the cycle}

The work of the EIVC cycle (Fig. 2) can be expressed as the sum of the absolute works of the individual processes:

$$
\mathrm{L}_{\mathrm{o}}=\mathrm{L}_{1-2}+\mathrm{L}_{2-3}+\mathrm{L}_{3-4}+\mathrm{L}_{4-5}+\mathrm{L}_{5-6}+\mathrm{L}_{6-7}+\mathrm{L}_{7-8}+\mathrm{L}_{8-9}+\mathrm{L}_{9-1}
$$

Substituting relations expressing the absolute works of the individual processes to the equation (7) the relative cycle work is obtained:

$$
\begin{aligned}
\frac{\mathrm{L}_{\mathrm{o}}}{\mathrm{p}_{0} \mathrm{~V}_{1}}= & \frac{1}{\kappa}-1 \\
\kappa & \left.\gamma \varphi\left[\varepsilon^{(\kappa-1)}-\varphi^{(\kappa-1)}\right]+\left(\frac{\varepsilon}{\varepsilon_{\mathrm{d}}}\right)^{(\kappa-1)}-\varepsilon^{(\kappa-1)}\right\}+ \\
& +\varepsilon^{(\kappa-1)} \gamma(\varphi-1)+\left(\frac{\varepsilon}{\varepsilon_{\mathrm{d}}}\right)^{\kappa}\left[\frac{\varepsilon_{\mathrm{d}}-1}{\varepsilon}-\frac{1+\frac{\Delta \mathrm{p}_{\mathrm{w}}}{\mathrm{p}_{0}}}{1-\frac{\Delta \mathrm{p}_{\mathrm{d}}}{\mathrm{p}_{0}}}\left(\frac{\varepsilon-1}{\varepsilon}\right)\right]
\end{aligned}
$$

where $\gamma$ and $\varphi$ are the load parameters: $\gamma=\frac{p_{3}}{p_{2}}, \quad \varphi=\frac{V_{4}}{V_{3}}$.
The specific work $\mathrm{L}_{\mathrm{o}} /\left(\mathrm{p}_{0} \mathrm{~V}_{1}\right)$ of the EIVC cycle versus control parameter $\varepsilon_{\mathrm{d}} / \varepsilon$ is presented in Fig. 6 and the cycle work in relation to the maximum work of the ideal SeiligerSabathe cycle is illustrated in Fig. 7. Characteristic curves in the both figures are near-linear which is beneficial for governing reasons.

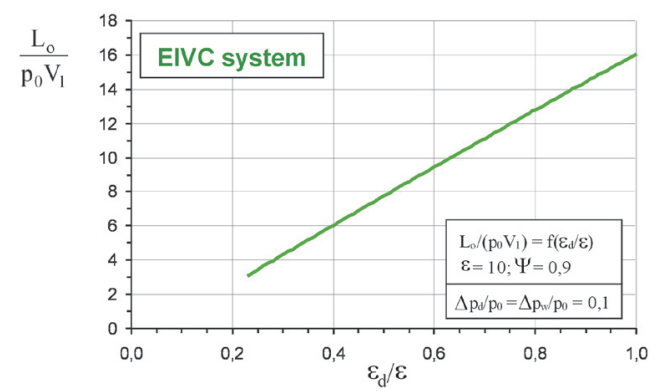

Fig. 6. Specific work $\mathrm{L}_{\mathrm{o}} /\left(\mathrm{p}_{0} \mathrm{~V}_{1}\right)$ of the EIVC cycle versus control parameter $\varepsilon_{\mathrm{d}} / \varepsilon$

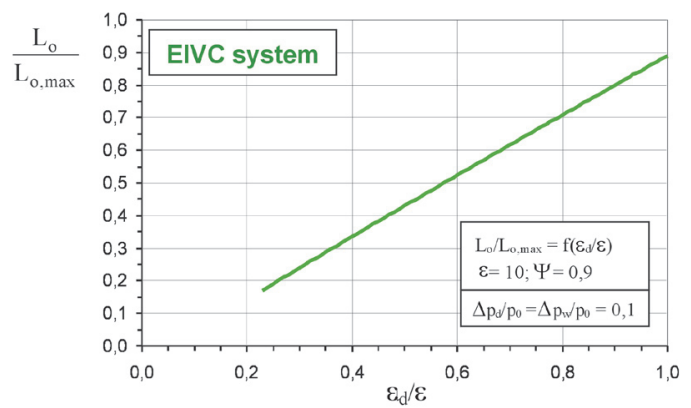

Fig. 7. Ratio of work of the EIVC cycle to the maximal work of the Seiliger-Sabathe cycle versus control parameter $\varepsilon_{\mathrm{d}} / \varepsilon$

\subsection{Charge exchange work}

The charge exchange work $\mathrm{L}_{\mathrm{w}}$ of the EIVC cycle (Fig. 2) can be expressed as the sum of the useful works of the individual processes:

$$
\mathrm{L}_{\mathrm{w}}=\mathrm{L}_{\mathrm{u}, 6-7}+\mathrm{L}_{\mathrm{u}, 7-8}+\mathrm{L}_{\mathrm{u}, 8-9}
$$

Then specific charge exchange work $\mathrm{L}_{\mathrm{w}}$ in relation to the product $\left(\mathrm{p}_{1} \mathrm{~V}_{1}\right)$ is obtained

$$
\frac{\mathrm{L}_{\mathrm{w}}}{\mathrm{p}_{1} \mathrm{~V}_{1}}=-\frac{\frac{\Delta \mathrm{p}_{\mathrm{w}}}{\mathrm{p}_{0}}(\varepsilon-1)+\frac{\Delta \mathrm{p}_{\mathrm{d}}}{\mathrm{p}_{0}}\left(\varepsilon_{\mathrm{d}}-1\right)}{\varepsilon\left(1-\frac{\Delta \mathrm{p}_{\mathrm{d}}}{\mathrm{p}_{0}}\right)}\left(\frac{\varepsilon}{\varepsilon_{\mathrm{d}}}\right)^{\kappa}
$$

The index $\mu$ of the relative charge exchange work is calculated by definition:

$$
\mu=\frac{\left|\mathrm{L}_{\mathrm{w}}\right|}{\mathrm{L}_{\mathrm{o}}},
$$

as a ratio of the charge exchange work (10) to the cycle work (8).

The theoretical Seiliger-Sabathe cycle with classic throttle governing of the SI engine load is the reference cycle for assessing the benefits of using the system with early inlet valve closure. Therefore for comparison, characteristics of 
the specific charge exchange work $\mathrm{L}_{\mathrm{w}} /\left(\mathrm{p}_{0} \mathrm{~V}_{1}\right)$ and the relative charge exchange work $\mu$ both for the open Seiliger-Sabathe cycle and EIVC cycle are presented in Figs 8 and 9. These works for EIVC cycle are much smaller in the entire load range except for full load.

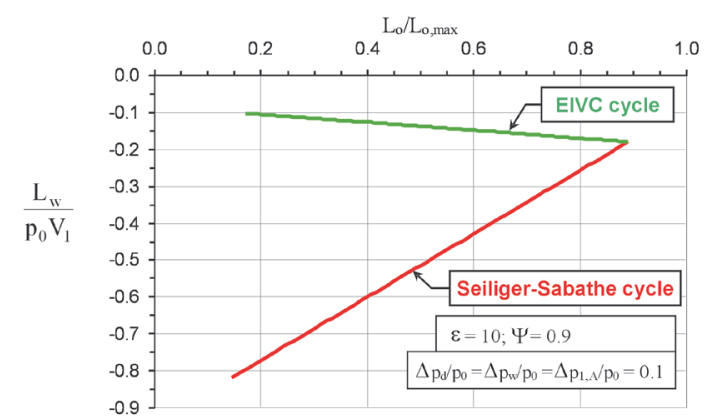

Fig. 8. Comparison of the specific charge exchange works $\mathrm{L}_{\mathrm{w}} /\left(\mathrm{p}_{0} \mathrm{~V}_{1}\right)$ for the EIVC cycle and Seiliger-Sabathe cycle versus work of the cycle

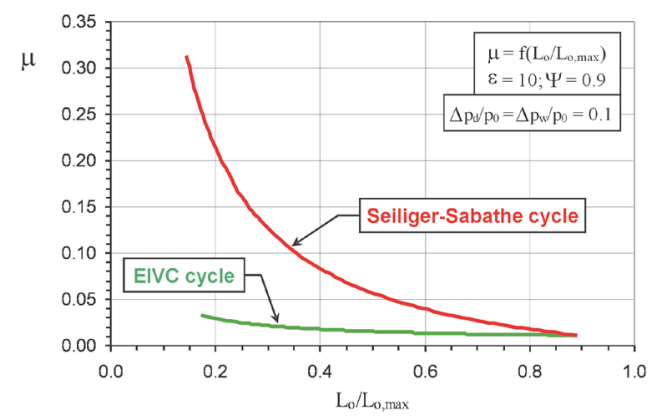

Fig. 9. Comparison of the relative charge exchange works $\mu$ for the EIVC cycle and Seiliger-Sabathe cycle versus work of the cycle

An important advantage of the EIVC system is reduction of the absolute value of the charge exchange work with the decrease of the engine load. For this reason, the relative charge exchange work $\mu$ for the EIVC system does not reach significant values (Fig. 9). Its maximum value does not exceed 3.5\% for the lowest load. The reverse, unfavorable situation is observed for Seiliger-Sabathe cycle - the absolute value of the charge exchange work significantly increases with a decrease of the load and the value of the relative charge exchange work exceeds $30 \%$.

\subsection{Efficiency of the cycle}

Efficiency of an ideal cycle is defined as a ratio of the cycle work $\mathrm{L}_{\mathrm{o}}$ to the supplied heat $\mathrm{Q}_{\mathrm{d}}$ :

$$
\eta_{\mathrm{o}}=\frac{\mathrm{L}_{\mathrm{o}}}{\mathrm{Q}_{\mathrm{d}}}
$$

which can also be formulated using the relative quantities:

$$
\eta_{\mathrm{o}}=\frac{\frac{\mathrm{L}_{\mathrm{o}}}{\mathrm{p}_{1, \mathrm{~A}} \mathrm{~V}_{1, \mathrm{~A}}}}{\frac{\mathrm{Q}_{\mathrm{d}}}{\mathrm{p}_{1, \mathrm{~A}} \mathrm{~V}_{1, \mathrm{~A}}}}=\frac{\frac{\mathrm{L}_{\mathrm{o}}}{\mathrm{p}_{1, \mathrm{~A}} \mathrm{~V}_{1, \mathrm{~A}}}}{\mathrm{E}_{0}}
$$

Next, inserting the energy-stoichiometric parameter $\mathrm{E}_{0}$ $[2,3]$ and (9) to (13), the following formula is obtained:

$$
\eta_{\mathrm{o}}=\frac{\kappa-1}{\varepsilon_{\mathrm{A}}^{(\kappa-1)}[\gamma-1+\kappa \gamma(\varphi-1)]}\left\{\begin{array}{c}
-\frac{\varepsilon_{\mathrm{A}}^{(\kappa-1)}-1}{\kappa-1}+\gamma(\varphi-1) \varepsilon \\
+\frac{\gamma \varphi}{\kappa-1}\left(\frac{\varepsilon_{\mathrm{A}}}{\varepsilon}\right)^{(\kappa-1)} \sum^{(\kappa-1)}- \\
\left(\begin{array}{c}
\frac{\Delta \mathrm{p}_{\mathrm{d}}}{\mathrm{p}_{0}}+\frac{\Delta \mathrm{p}_{\mathrm{w}}}{\mathrm{p}_{0}} \\
1+\frac{\Delta \mathrm{p}_{1, \mathrm{~A}}}{\mathrm{p}_{0}}
\end{array}\right)\left(\frac{\varepsilon-1}{\varepsilon_{\mathrm{A}}}\right) .
\end{array}\right.
$$

The efficiency $\eta_{0}$ is significant parameter which enables assessment of the cycle in the energy aspect. Comparison of the cycle efficiencies for the system with early inlet valve closure and the open Seiliger-Sabathe cycle depending on the cycle works is presented in Fig. 10.

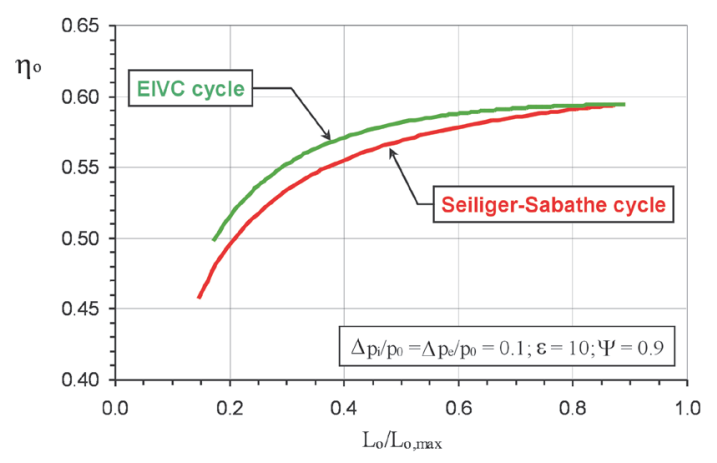

Fig. 10. Comparison of the efficiencies no of the EIVC cycle and Seiliger-Sabathe cycle versus work of the cycle

The energy efficiency of the EIVC cycle is higher by 2 percentage points than the efficiency of the open SeiligerSabathe cycle almost in the entire load range.

\section{Conclusion}

The theoretical research on the system with independent, early inlet valve closure has been conducted. The open, ideal cycle has been assumed as a model of the processes proceeding in a combustion engine working according to the analysed system. The theoretical Seiliger-Sabathe cycle with classic throttle governing of an engine load is the reference cycle for evaluation of benefits and the work effectiveness of EIVC. The effects of use of the investigated system can be expressed best of all by the energy efficiency of the cycle. At all conditions except full load, this efficiency for EIVC is higher than the Seiliger-Sabathe cycle. The consequence of increased efficiency is reduction of fuel consumption. Fuel economy can reach up to $4 \%$ under light load operating conditions. These benefits are due to a significant reduction in the charge exchange work because early inlet valve closure allows the elimination of the throttle from intake system of SI engine. Thus, the SI engine load control by EIVC strategy gives the desired effects.

Investigations on variable valve actuation are conducted by many scientific as well as research and development centres. This testifies topicality of the presented problems. 


\section{Acknowledgements}

This scientific work was supported by Faculty of Power and Environmental Engineering of the Silesian University of Technology within the statutory research.

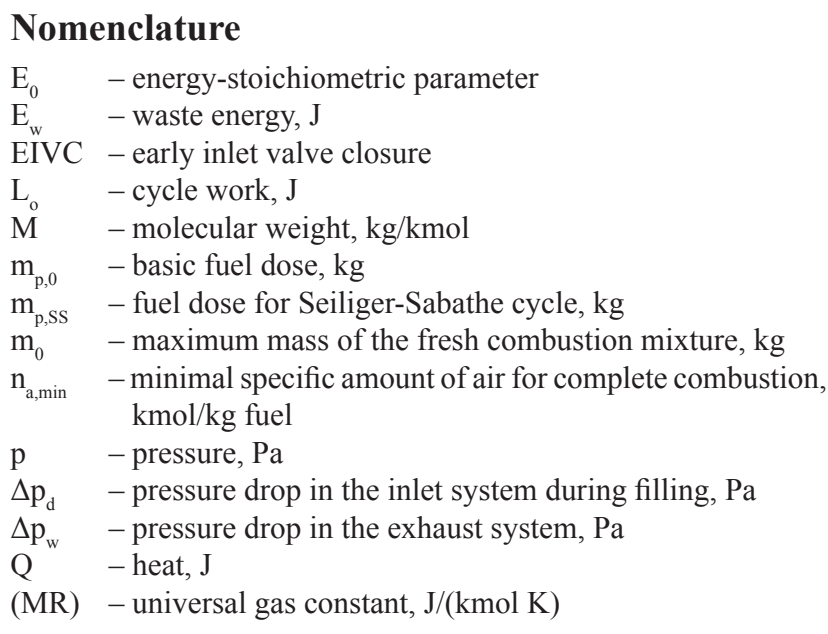

\section{Bibliography}

[1] Żmudka Z., Postrzednik S. Flow resistance in the engine inlet-exhaust system as affected by the engine parameters. Combustion Engines 2009 1(136).

[2] Żmudka Z. Energy and ecological aspects of the charge exchange process improvement in an internal combustion engine. Silesian University of Technology Publishing House, Gliwice 2010.

[3] Postrzednik S., Żmudka Z. Application research on procedures for independent control of the internal combustion engine valves. Project nr N502 026 32/2190. PBU-30/RIE-6/07, Report, Gliwice 2009.

[4] Żmudka Z., Postrzednik S., Przybyła G. Late intake valve closing as a way of the throttleless control of SI engine load. Journal of KONES - Powertrain and Transport, 2012 19(1) 491-499.

[5] Żmudka Z., Postrzenik S., Przybyła G. Realization of the Atkinson-Miller cycle in spark-ignition engine by means of the fully variable inlet valve control system. Archives of Thermodynamics, 2014 35(3) 191-205.

[6] Cope D., Wright A., Corcoran C., Pasch K. Fully flexible electromagnetic valve actuator: design, modeling, and measurements. SAE Technical Paper, No. 2008-01-1350, 2008.

Zbigniew Żmudka, DSc., DEng. - Faculty of Power and Environmental Engineering, Silesian University of Technology, Gliwice, Poland.

e-mail: zbigniew.zmudka@polsl.pl

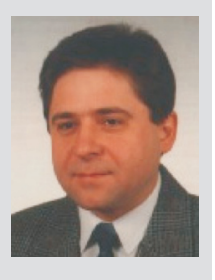

Prof. Stefan Postrzednik, DSc., DEng. - Faculty of Power and Environmental Engineering, Silesian University of Technology, Gliwice, Poland. e-mail: stefan.postrzednik@polsl.pl
SI - spark ignition

$\mathrm{T} \quad$ - temperature, $\mathrm{K}$

$\mathrm{T}_{0} \quad$ - temperature of the fresh charge, $\mathrm{K}$

$\mathrm{V}^{0}-$ volume, $\mathrm{m}^{3}$

$\mathrm{V}_{\mathrm{d}, \mathrm{z}} \quad$ - cylinder volume at the moment of the inlet valve closure, $\mathrm{m}^{3}$

$\mathrm{X}^{\mathrm{d}, \mathrm{z}} \quad$ - humidity, $\mathrm{kmol} \mathrm{H}_{2} \mathrm{O} / \mathrm{kmol} \mathrm{d.g.}$

\section{Greek symbols}

$\gamma, \varphi \quad$ - load parameters

$\varepsilon \quad$ - compression ratio

$\varepsilon_{\mathrm{d}} \quad-$ load control parameter for EIVC system

$\eta_{0} \quad-$ thermal efficiency of a cycle

$\kappa \quad-$ isentropic exponent

$\lambda-$ excess air number

$\lambda_{0}-$ excess air number for maximal mass of the fresh charge

$\mu \quad-$ relative charge exchange work

$\Psi \quad$ - heat distribution number

[7] Picron V., Postel Y., Nicot E., Durrieu D. Electro-magnetic valve actuation system: first steps toward mass production. SAE Technical Paper No. 2008-01-1360, 2008.

[8] Bernard L., Ferrari A., Micelli D., Perotto A., Rinolfi R., Vattaneo F. Elektrohydraulische Ventilsteuerung mit dem „MultiAir"-Verfahren. MTZ, 12, 2009.

[9] Bernard L., Ferrari A., Rinolfi R., Vafidis C. Fuel economy improvement potential of UniAir throttle-less technology. ATA International Symposium on "SIE: the CO2 challenge", paper 02A5012, Venice 2002.

[10] Haas M., Rauch M. Electro-hydraulic fully variable valve train system. ATZ autotechnology, 2010, 10(02).

[11] Franca O.M. Impact of the Miller cycle in the efficiency of an FVVT engine during part load operation. SAE Tech. Paper, No 2009-36-0081, 2009.

[12] Jia M., Li Y., Xie M., Wang T. Numerical evaluation of the potential of late intake valve closing strategy for diesel PCCI (premixed charge compression ignition) engine in a wide speed and load range. Energy 2013, 51, 203-215.

[13] Gonca G., Sahin B., Ust Y. Performance maps for an air-standard irreversible Dual-Miller cycle (DMC) with late inlet valve closing (LIVC) version. Energy 2013, 54, 285-290.

[14] Begg S.M., Hindle M.P., Cowell T., Heikal M.R. Low intake valve lift in a port fuel-injected engine. Energy 2009, 34, 2042-2050.

[15] Clenci A.C., Iorga-Siman V., Deligant M., Podevin P., Descombes G., Niculescu R. A CFD (computational fluid dynamics) study on the effects of operating an engine with low intake valve lift at idle corresponding speed. Energy 2014, 71, 202-217.

[16] Zammit J.P., McGhee M.J., Shayler P.J., Lawa T., Pegg I. The effects of early inlet valve closing and cylinder disablement on fuel economy and emissions of a direct injection diesel engine. Energy 2015, 79, 100-110.

Grzegorz Przybyła, DEng. - Faculty of Power and Environmental Engineering, Silesian University of Technology, Gliwice, Poland.

e-mail: grzegorz.przybyla@polsl.pl 